\title{
Scenarios for a Worldwide Deployment of Nuclear Power Full Report
}

E. Merle-Lucotte, D. Heuer, C. Le Brun, J.M. Loiseaux LPSC, 53 avenue des Martyrs, F-38026 Grenoble Cedex, FRANCE (merle@lpsc.in2p3.fr)

July 2005

The present report provides a more complete version of our studies with all details necessary for a full understanding. 


\section{Contents}

1 Introduction 3

2 Basic Data: Energy Demand and Resource Availability 4

2.1 Energy Demand Projections . . . . . . . . . . . . . . . . . 4

2.2 Natural Uranium and Thorium Resources . . . . . . . . . . . . . 6

2.3 Using the Basic Data in the Parametrized Calculations . . . . . . . . 7

$\begin{array}{lll}3 & \text { Scenario with Light Water Reactors } & \mathbf{7}\end{array}$

3.1 Reactor Types in the Scenario . . . . . . . . . . . . . . . . . 8

3.2 Characteristics of existing Light Water Reactors . . . . . . . . . . . 8

3.3 Characteristics for Future Light Water Reactors . . . . . . . . . . . . 9

3.4 Deployment Scenarios Considered . . . . . . . . . . . . . . . . 9

3.4.1 Current Uranium Resource Handling . . . . . . . . . . . . . 10

3.4.2 Fuel Handling Optimized to Spare Uranium Reserves . . . . . 11

4 Scenario with Light Water and Fast Neutron Reactors $\mathbf{1 3}$

4.1 Characteristics of the Fast Neutron Reactors (FNR) Considered . . . 13

4.2 Characteristics of the Light Water Reactors involved . . . . . . . . . 15

4.3 Scenario with liquid metal cooled FNRs . . . . . . . . . . . . . . 15

4.4 Scenario with gas cooled FNRs . . . . . . . . . . . . . . . 17

4.5 Scenario with liquid metal cooled FNRs started either with Plutonium or with ${ }^{235} \mathrm{U} \ldots \ldots \ldots \ldots . \ldots \ldots$

5 Scenario with Light Water and Molten Salt Reactors 19

5.1 Characteristics of the Molten Salt Reactor involved . . . . . . . . . 20

5.2 Characteristics of the Light Water Reactors involved . . . . . . . . 20

5.3 Deployment result with Light Water Reactors and Molten Salt Reactors 22

6 Scenario with Light Water Reactors, FNRs and TMSRs 23

6.1 Characteristics of the Light Water Reactors involved . . . . . . . . . 23

6.2 Fast Neutron Reactors involved . . . . . . . . . . . . . . . . . 23

6.3 Molten Salt Reactors involved: TMSR . . . . . . . . . . . . . . . . 24

6.4 Deployment Results including Light Water Reactors, Liquid Metal Cooled FNRs and TMSRs . . . . . . . . . . . . . . . . . 25

$\begin{array}{lll}7 & \text { Conclusions and Prospects } & 27\end{array}$ 


\section{Introduction}

The growing worldwide demand for energy must be controlled, this is a necessity. However, even in the event of very voluntary policies to dampen energy demand, it is hard to imagine that the demand could be less than twice as much as today by 2050 . We feel it is necessary to satisfy this demand. It is obvious also that greenhouse gas emissions must be reduced in order to limit the dramatic consequences they entail. An energy shortage could develop if new sources of massive energy production were not established. A significant contribution of nuclear power to such massive energy production by 2050 rests on a well coordinated and optimized deployment scheme [1][2]. This requires, as early as today, a reflection on the present status of nuclear power, on its extrapolation into the future and, thus, on the means that should be put to work and the transition possibilities.

Several major problems at issue motivate the present study: the reserves of ${ }^{235} \mathrm{U}$, the only natural fissile nucleus, are limited; more intensive production of nuclear power with the current technology could lead to a rapid depletion of the resource. Moreover, the advent of new reactor technologies based on the other two accessible fissile elements, namely plutonium and ${ }^{233} \mathrm{U}$, requires that the production of these two elements be planned in advance, since they are not naturally available.

The deployment of nuclear power, if it is to be well coordinated and successful, must take many factors in consideration among which:

- what will the worldwide energy demand be and, more specifically, to what extent will nuclear power be expected to contribute

- what are the reserves for the resources involved (uranium, thorium) and the stockpiles of fissile material (plutonium, ${ }^{233} \mathrm{U}, \ldots$ )

- what will the technologies be in the coming years (reactor type, fuel cycle), what are their characteristics, what is the radio-toxicity induced by the wastes generated.

Our aim in this work is to explore the potential for worldwide nuclear power deployment and its limitations. In this view, we pay particular attention to the availability of uranium 235, the only natural fissile element, which is, as a consequence, the major constraining factor in the frame of sustainable development. Secondly, we evaluate the possibility of eventually shutting down the reactor fleets started, taking in consideration only the heavy nuclei whose handling is tricky. The fission products generated are the same in all the deployment scenarios so that they are not considered in our discussion. 
The complex interweaving of the factors and constraints involved has made the use of a dedicated program necessary. We have developed a parameterized calculation algorithm [3] that helps us examine how nuclear power can best respond in a sustainable way to an intense energy demand.

The first section in this paper exposes the data, in terms of energy needs and available resources, on which the rest of the work is based. It also shows how these data are taken into account in the parameterized algorithm we use to evaluate the deployment of nuclear power. The scenarios considered are explained in the subsequent sections, along with the results we have obtained so far, in terms of reactor deployment and resource depletion.

In this paper, the need to produce large amounts of fissile matter will appear. Such production, and the degree of breeding, depend a great deal on the technology of the reactors considered. We have used estimations, pending more hardcore data to be obtained from work currently in progress in CNRS (french National Center of Scientific Research) laboratories. These estimations already give an idea of the constraints that come into play in the deployment of nuclear power.

\section{Basic Data: Energy Demand and Resource Avail- ability}

\subsection{Energy Demand Projections}

The projected evolution of energy needs that we have selected for our scenarios is inspired from that published by R.P. Bauquis [4]. This (see Table 1) projects a world population of 8 to 10 billion by 2050 and takes into account potential restrictions on fossil fuels, in particular on oil and gas.

\begin{tabular}{|c|c|c|c|}
\hline & 2000 & 2020 & 2050 \\
\hline Population & 6 billion & 7.5 billion & $8-10$ billion \\
\hline Total Primary Energy & 9,3 GToe & 14 GToe & 18 GToe \\
\hline $\begin{array}{l}\text { Fossil Fuel (oil+gas+coal) } \\
\text { Share }\end{array}$ & $\begin{array}{l}8 \text { GToe } \\
(85 \%)\end{array}$ & $\begin{array}{l}\text { 12,2 GToe } \\
(87 \%)\end{array}$ & $\begin{array}{l}\text { 12,6 GToe } \\
(70 \%)\end{array}$ \\
\hline $\begin{array}{l}\text { Renewable + Hydroelectric } \\
\text { Share }\end{array}$ & $\begin{array}{l}0,7 \text { GToe } \\
(7,5 \%)\end{array}$ & $\begin{array}{l}0,9 \text { GToe } \\
(6,5 \%)\end{array}$ & $\begin{array}{l}1,4 \text { GToe } \\
(8 \%)\end{array}$ \\
\hline $\begin{array}{l}\text { Nuclear Power } \\
\text { Share }\end{array}$ & $\begin{array}{l}0,6 \text { GToe } \\
(6,5 \%)\end{array}$ & $\begin{array}{l}0,9 \text { GToe } \\
(6,5 \%)\end{array}$ & $\begin{array}{l}4 \text { GToe } \\
(22 \%)\end{array}$ \\
\hline
\end{tabular}

Table 1: Energy need projection until 2050 according to R.P. Bauquis. (GToe: billion ton oil equivalent) 
Similar projections can be worked out using a simple formula and making a few assumptions, in particular that of a stabilization of fossil fuel consumption at its current level. To evaluate the evolution of worldwide energy demand, we can write it as:

$$
E=\frac{\mathrm{E}}{\mathrm{GNP}} * \frac{\mathrm{GNP}}{\mathrm{N}} * \mathrm{~N}
$$

with $\quad-\mathrm{N}$ : world population

- GNP/N : per capita gross national product

- E/GNP : energy intensity

According to demographic estimations, the world population should grow from 6 billion in 2000 to about 9 billion in 2050, yielding a 3/2 term in the formula above. The annual economic growth (per capita GNP) is projected to be $1.5 \%$ in the more pessimistic scenarios up to $3 \%$ in the more optimistic view. The GNP/N term is then multiplied by something between 2.1 and 4.4. Energy intensity could induce a factor of 0.5 in the formula above if energy savings are included in this term. The worldwide energy demand could thus grow by a factor between 1.6 and 3.3. In this paper, we use a low intermediate value: we assume the energy demand will double by 2050 .

We now need to estimate the share of nuclear power in this worldwide production of energy. We made the following choices:

- to maintain the use of fossil fuels at its current level

- to attribute an equal share of the demand to new renewable energies and to nuclear power.

The resulting energy mix is summarized in Table 2 .

\begin{tabular}{|c||c|c|}
\hline Primary Energy (GToe) & 2000 & 2050 \\
\hline \hline Fossil fuels & 8 & 8 \\
\hline $\begin{array}{c}\text { Hydro power \& } \\
\text { New renewables }\end{array}$ & 0.7 & 5.3 \\
\hline Nuclear power & 0.6 & 5.3 \\
\hline \hline Total & 9.3 & 18.6 \\
\hline
\end{tabular}

Table 2: Contribution of the commercial primary energy sources in 2000 and our projection for 2050.

These numbers show that the production of nuclear power is multiplied by a factor close to 8 by 2050. This is the energy scenario that we have applied in the work we describe below. We would like to stress that such a scenario, which is very optimistic as to the energy savings term and as to the contribution of the new renewable energies, still does not reduce greenhouse gas emissions, since the contribution of fossil fuels has been stabilized but not reduced. The demand on nuclear power is thus probably underestimated. Similar projections have been found in other studies [5][6]. 
We now turn our attention to the prospective evolution of nuclear power capacity. All the deployment scenarios described below rest on the target progression given in Table 3): starting at zero in 1970, nuclear power production rises to 1800 TWhe (tera Watt hours of electric power) in 1985, to 2400 TWhe in 2000. Nuclear power remains stable from 2000 to 2015 , then increases at the rate of $6.2 \%$ per year until 2050 , achieving the eightfold increase by 2050 ; it then slowly increases by $1.1 \%$ per year until 2100. Extrapolating up to 2100 allows us to verify that the deployment scenarios are lasting.

\begin{tabular}{|c|c|c|c|c|}
\hline 1970 & 2000 & 2015 & 2050 & 2100 \\
\hline \hline 0 TWhe & 2400 TWhe & 2800 TWhe & 18000 TWhe & 32400 TWhe \\
\hline \hline 0 GWe.year & 340 GWe.year & 400 GWe.year & 2570 GWe.year & 4630 GWe.year \\
\hline
\end{tabular}

Table 3: Projection for nuclear power production up to 2100 - extrapolation from references [4][5][6], in TeraWatt-hour electric (TWhe) units, and in GigaWatt electricyear (GWe.year) units considering a reactor efficiency of $80 \%$.

In the next sections, we simulate the deployment of several reactor technologies and examine how well they satisfy the anticipated energy demand:

- The first simulation relies only on light water reactors.

- A second simulation involves light water reactors and fast neutron reactors (FNRs) [10] ;

- A third simulation involves light water reactors and molten salt reactors (MSRs) which operate with a thermal neutron spectrum and are based on a ${ }^{232} \mathrm{Th}^{2}{ }^{233} \mathrm{U}$ fuel cycle

- Our last simulation involves all the above reactor types - light water reactors, U-Pu based FNRs, and ${ }^{232} \mathrm{Th}^{233} \mathrm{U}$ based MSRs [10].

\subsection{Natural Uranium and Thorium Resources}

Workable natural uranium resources are sorted according to extraction cost. The amount of the resource that has already been extracted is estimated at 2 million metric tons of uranium (MtU) [11]. The established reserves for an extraction cost of $\$ 40 / \mathrm{kgU}$ amount to $1.6 \mathrm{MtU}$; they amount to $2.6 \mathrm{MtU}$ at a cost of $\$ 80 / \mathrm{kgU}$, representing 40 years of consumption at the current level. The estimation of the total natural uranium resource is a function of the technology and of the acceptable extraction costs. Today, the average uranium extraction cost is $\$ 30 / \mathrm{kgU}$; extrapolating to an extraction cost of $\$ 400 / \mathrm{kgU}$ gives a total amount of $23 \mathrm{MtU}$ [11]. It is intentionally that we use this optimistic value for the limit on the natural uranium resource in our deployment scenarios. Most authors take 8 to $17 \mathrm{MtU}$ as the limit on the resource[12]. 
Just like uranium 238, thorium 232 is a fertile material: it can be converted to uranium 233 which is fissile. Thorium resources are abundant, they are estimated to be twice or three times as large as those of uranium. In our scenarios, however, and because the reactors considered consume a small fraction of the fertile matter in the natural resource, we have set the same limit on the thorium resource and on the uranium resource so that it is easier to compare the evolution of these two quantities.

\subsection{Using the Basic Data in the Parametrized Calculations}

For each year of the deployment simulation, nuclear reactors are started up as needed to satisfy the target energy demand. The type of reactor that is started is chosen as follows:

- the highest priority reactor type is selected;

- the amount of fuel required to operate the reactor during its entire life is calculated;

- if enough fuel is available from the stocks at all times during the reactor's lifespan, the reactor is started and this process is repeated until the year's target energy demand is satisfied;

- if, at any time in the reactor's lifespan, there is not enough fuel to operate it, fuel manufacturing units, i.e. enriching and reprocessing units, are started. Two possibilities arise:

- the fuel units have enough raw material (natural or produced in other reactors that are already in operation) to manufacture the fuel necessary for the reactor being considered. The reactor is started and the process is pursued with another reactor of the higher priority type until the target energy demand for the year is satisfied;

- the resources needed to manufacture the fuel run out before the end of the reactor's lifespan. The possibility of starting another, lower priority type of reactor is examined, using the same procedure. If no reactor can be started, the target world energy demand is out of reach for the set of reactor types specified and the deployment year concerned.

\section{$3 \quad$ Scenario with Light Water Reactors}

In our first scenario, nuclear power production is based solely on reactors in which ordinary water is the moderator and the fuel is based on enriched uranium. This is the prevalent reactor type today, it accounts for $87 \%$ of worldwide nuclear power production. The remaining $13 \%$ are produced by heavy water moderated reactors called CANDU (CANadian Deuterium Uranium) and water-graphite reactors called GLWR (Graphite Light Water Reactor)[7]. 


\subsection{Reactor Types in the Scenario}

Light water reactors imply a thermal neutron spectrum, ordinary water serving as both moderator and coolant. Two types of light water reactors are involved in our simulation: the pressurized water reactors (PWR) as currently used in France, and the future European $\mathrm{EPR}^{1}$ (European Pressurized Reactor). Their general properties are listed in Table 4.

\begin{tabular}{|l||l|l|}
\hline & PWR & EPR \\
\hline \hline Output capacity & $1.0 \mathrm{GWe}$ & $1.45 \mathrm{GWe}$ \\
\hline Load factor & 0.8 & 0.8 \\
\hline First operating date & 1970 & 2010 \\
\hline Reactor lifespan & $40 \mathrm{yrs}$ & $50 \mathrm{yrs}$ \\
\hline
\end{tabular}

Table 4: General properties of the light water reactors used in the scenario

\subsection{Characteristics of existing Light Water Reactors}

In PWRs, the fuel is enriched natural uranium (UOX). The characteristics of the fuel and the amount required per GWe.year of energy produced are given in Table 5, as well as the ensuing wastes.

Natural uranium enriching plants are included in our simulation, they process natural uranium to produce the fuel required for the reactors. The output of these plants is enriched and depleted uranium with the enriching ratios shown in Table 5.

\begin{tabular}{|l||c|}
\hline & PWR \\
\hline \hline Type of fuel & UOX \\
\hline${ }^{235}$ U enriching ratio for the fuel & $\mathbf{3 . 5 \%}$ \\
\hline${ }^{235}$ U enriching ratio of & $\mathbf{0 . 3 \%}$ \\
rejected depleted uranium & $\mathbf{1 \%}$ \\
\hline${ }^{235}$ U enriching ratio of the fuel unloaded & \\
(before fuel reprocessing) & $\mathbf{2 7 . 2}$ tons \\
\hline Amount of fuel loaded & 179.8 tons \\
Corresponding amount of depleted uranium & 207 tons \\
Corresponding amount of natural uranium & $\mathbf{2 6}$ tons \\
\hline Amount of spent fuel after reprocessing & $\mathbf{2 7 0 ~} \mathbf{~ g}$ \\
\hline Amount of plutonium & \\
\hline
\end{tabular}

Table 5: Characteristics of PWR fuel. The amounts are given in metric tons and per GWe.year of energy produced.

\footnotetext{
${ }^{1}$ EPR has been chosen as an instance of a third generation reactor. Choosing a different third generation reactor would not change the conclusions reached for this scenario.
} 


\begin{tabular}{|c|c|c|c|}
\hline & No Multirecycling & $\begin{array}{c}\text { Case 2: } \\
\text { Plutonium } \\
\text { Multirecycling }\end{array}$ & $\begin{array}{c}\text { Case 3: } \\
\text { Pu }+ \text { MA } \\
(\mathrm{Np}, \mathrm{Am}, \mathrm{Cm}) \\
\text { Multirecycling }\end{array}$ \\
\hline Type of fuel & UOX & MOX-UE & MOX-UE \\
\hline${ }^{235} \mathrm{U}$ enriching ratio of fuel & $4.9 \%$ & $4.5 \%$ & $4.7 \%$ \\
\hline $\begin{array}{l}{ }^{235} \mathrm{U} \text { enriching ratio of } \\
\text { rejected depleted } \mathrm{U}\end{array}$ & $0.25 \%$ & $0.25 \%$ & $0.25 \%$ \\
\hline $\begin{array}{l}\text { Pu \& MA enriching ratio } \\
\text { of fuel }\end{array}$ & $0 \%$ & $2.1 \%$ & $3.7 \%$ \\
\hline $\begin{array}{l}\text { Fuel amount loaded } \\
\text { Of which } \mathrm{Pu} / \mathrm{Np} / \mathrm{Am} / \mathrm{Cm}(\mathrm{kg})\end{array}$ & $\begin{array}{l}\text { 13.6 tons } \\
0 / 0 / 0 / 0\end{array}$ & $\begin{array}{l}13.6 \text { tons } \\
285 / 0 / 0 / 0\end{array}$ & $\begin{array}{c}\mathbf{1 3 . 6} \text { tons } \\
387 / 17 / 43 / 60\end{array}$ \\
\hline $\begin{array}{l}\text { Corresponding natural U } \\
\text { Corresponding depleted U }\end{array}$ & $\begin{array}{l}138 \text { tons } \\
124.4 \text { tons }\end{array}$ & $\begin{array}{l}122 \text { tons } \\
108.7 \text { tons }\end{array}$ & $\begin{array}{l}126.3 \text { tons } \\
113.2 \text { tons }\end{array}$ \\
\hline $\begin{array}{l}\text { Uranium recovered after } \\
\text { processing }\end{array}$ & 12.6 tons & 12.4 tons & 12.3 tons \\
\hline Pu produced & $170 \mathrm{~kg}$ & $285 \mathrm{~kg}$ & $387 \mathrm{~kg}$ \\
\hline Pu placed in storage & $170 \mathrm{~kg}$ & $0 \mathrm{~kg}$ & $0 \mathrm{~kg}$ \\
\hline
\end{tabular}

Table 6: Characteristics of the fuel for the future EPR [8][9]. Amounts are given per GWe.year of energy produced.

\subsection{Characteristics for Future Light Water Reactors}

For the future EPR, three types of fuel [8][9][10] were considered, in order to evaluate the impact the fuel option can have on the nuclear power deployment scenarios (see Table 6):

- a ${ }^{235} \mathrm{U}$ enriched natural uranium fuel similar to the one used in the PWRs above;

- a fuel based on multi-recycled plutonium, i.e. a mixture of recycled plutonium and enriched uranium (labeled MOX-UE);

- a fuel based on the multi-recycling of plutonium, americium, neptunium and curium, mixed, as above, with enriched uranium.

\subsection{Deployment Scenarios Considered}

For each of the possible EPR fuels, two cases have been considered, namely the current handling of uranium, and uranium handling that is better optimized to spare the uranium resource. 


\subsubsection{Current Uranium Resource Handling}

With the current uranium resource handling, at the end of the enriching phase, the depleted uranium contains 0.25 to $0.3 \%{ }^{235} \mathrm{U}$. This depleted uranium is considered as waste, and so is the uranium from the spent fuel after reprocessing. The nuclear power deployment scenario in this case is shown in Figure 1, and the stocks of natural uranium and of plutonium are shown in Figure 2.
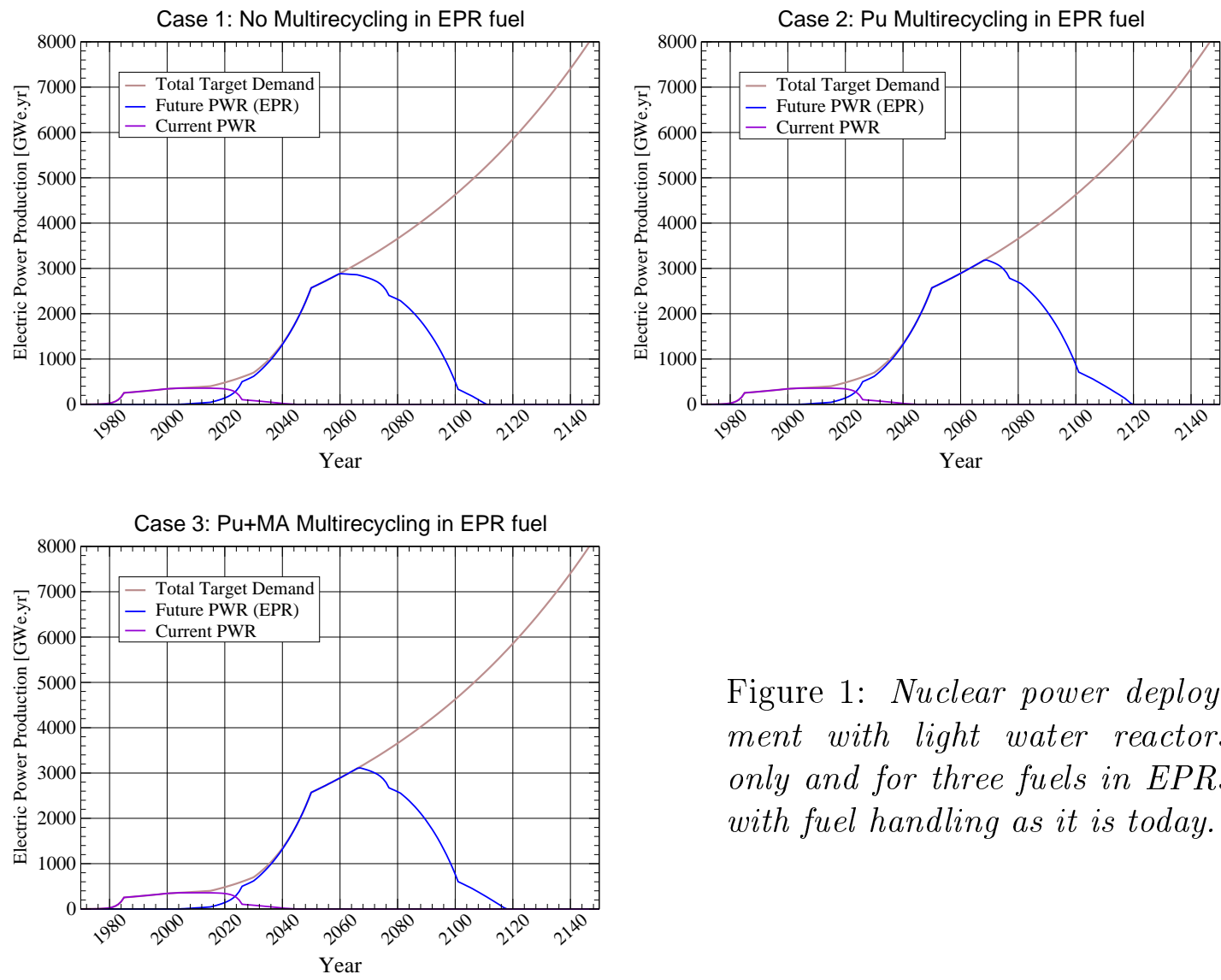

Figure 1: Nuclear power deployment with light water reactors only and for three fuels in EPRs with fuel handling as it is today.

We find that, with light water reactors only, and with this kind of fuel handling, the target nuclear power deployment is out of reach because of the rapid depletion of the economically accessible natural uranium resource. Nuclear power generation comes rapidly to a halt for lack of fuel. This occurs sooner or later, depending on the fuel used:

- With UOX fuel in the EPRs, by 2030, the installed capacity is twice that of today, and the substitution of today's reactors with EPRs is achieved. Nuclear power capacity continues to grow until 2060, reaching a maximum capacity of 2900 GWe. The natural uranium resource is drained so that it becomes impossible to start new reactors beyond 2060; the little uranium that is still available is necessary to feed the reactors that are already running. This shows in Figure 1 with the sudden breakoff of the EPR curve. In real life, this breakoff in energy generation shown in the figures should be smoother because of various factors (uranium price, discovery of new extraction potential, ...). 

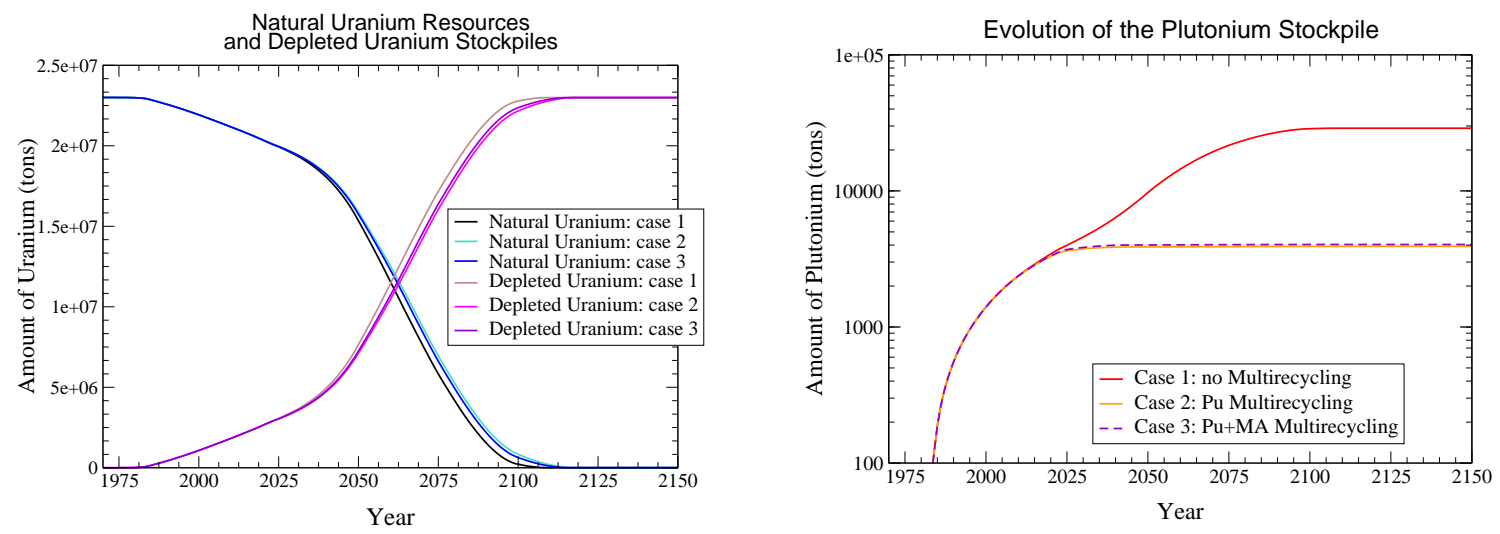

Figure 2: Natural uranium and plutonium stockpiles with light water reactors only and for three fuels in EPRs with fuel handling as it is today.

- With multi-recycled plutonium on enriched uranium in EPRs, nuclear power deployment can extend to 2070, reaching a maximum capacity of 3200 GWe. The ${ }^{235} \mathrm{U}$ enriching ratio required to produce $1 \mathrm{GWe}$ is reduced, thanks to the presence of another fissile element, plutonium. As a result, the draining of the natural uranium reserves is somewhat slower. One should note, however, that, if $\mathrm{Pu}$ based reactors were to be included in the set of reactors being considered (see below), Pu multi-recycling in EPRs would be a problem, as EPRs make poor use of the $\mathrm{Pu}$ resource; they degrade the quality of the plutonium without consuming it entirely.

- The multi-recycling of minor actinides (Np, Am, Cm) along with the $\mathrm{Pu}$ is less efficient for the production of energy than $\mathrm{Pu}$ multi-recycling alone. The uranium that is mixed with the $\mathrm{Pu}$ and minor actinides has to have a higher enriching ratio because of the presence of neutron consuming elements. The natural uranium resources are drained faster than in the preceding situation: nuclear power capacity stops growing in 2065, reaching a low maximum of 3100 GWe. As a result, this fuel is not given further consideration in our scenarios.

\subsubsection{Fuel Handling Optimized to Spare Uranium Reserves}

Today, the fuel cycle is open, the spent fuel is not recycled. It is stored as is, pending possible recycling decisions. Some countries such as France have opted for fuel recycling: the plutonium and the uranium in the spent fuel are separated. A fraction of the plutonium is recycled in MOX fuel, the reprocessed uranium is put in storage for the time being, in the event of future valorization. It would be possible to re-enrich the reprocessed uranium and use it as fuel. It would also be possible to reduce to $0.1 \%$ the ${ }^{235} \mathrm{U}$ content of the depleted uranium from the enriching process. These options could become economically worthwhile if the costs of fossil fuels and of natural uranium were to increase.

The results for the corresponding nuclear deployment scenario and the stocks of 

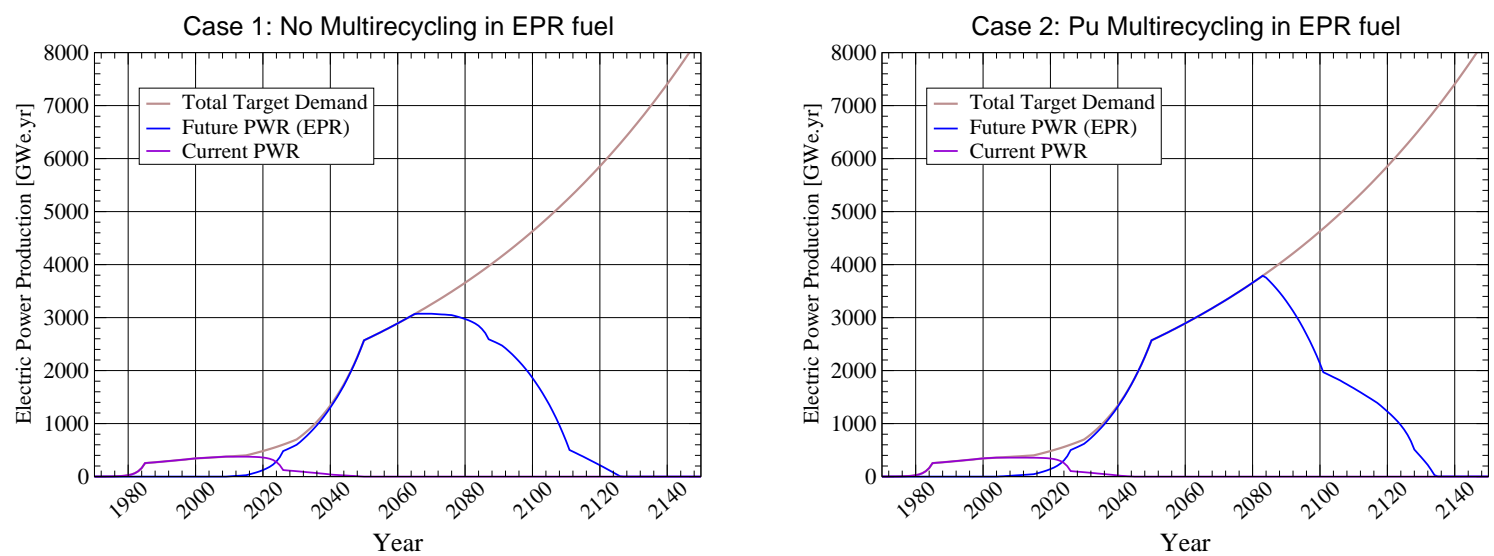

Figure 3: Nuclear power deployment with light water reactors only and for two fuels in EPRs, with fuel handling optimized to spare uranium reserves: EPR without multirecycling (case 1) and EPR with Pu multirecycling (case 2).
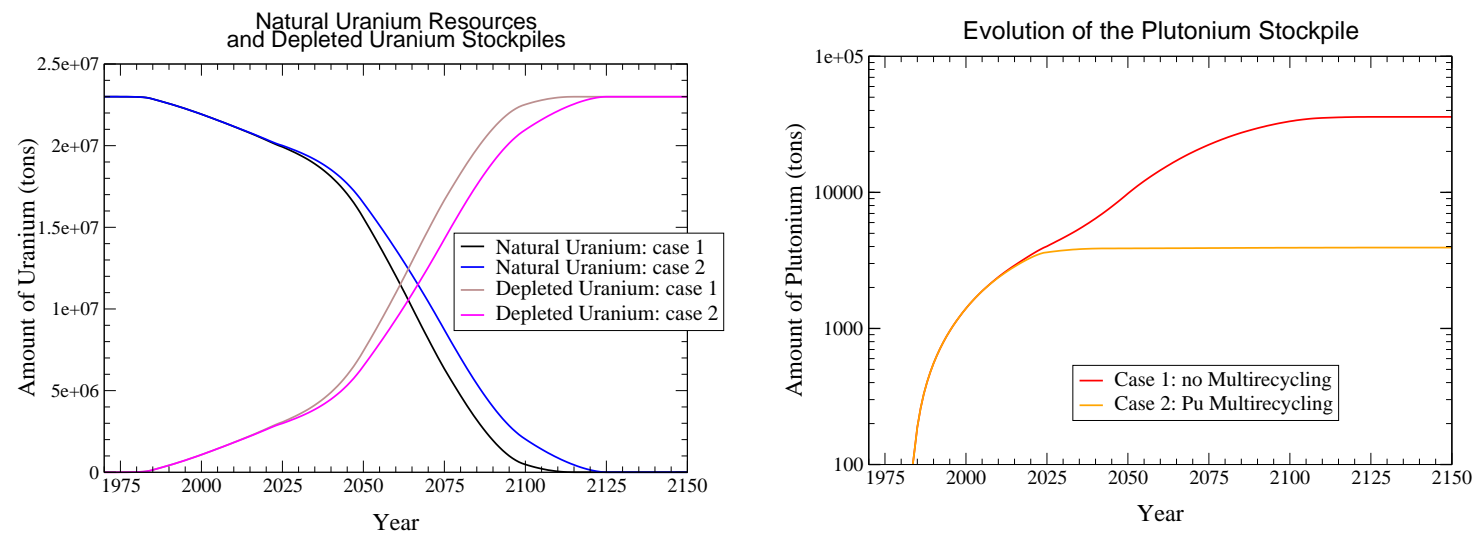

Figure 4: Natural uranium and plutonium stockpiles with light water reactors only and for two fuels in EPRs, with fuel handling optimized to spare uranium reserves: EPR without multirecycling (case 1) and EPR with Pu multirecycling (case 2). 
plutonium and of natural uranium are shown in Figures 3 and 4:

- With UOX fuel in the EPRs (case 1), nuclear power generation can continue to grow until 2065, reaching a maximum capacity of 3100 GWe.

- With multi-recycled plutonium on enriched uranium (case 2), nuclear power deployment using EPRs can extend to 2085, reaching a maximum capacity of 3900 GWe, i.e. 15 years longer than in the preceding sub-section, with the same fuel and no fuel handling optimization.

This last option is the best one if only light water reactors are considered. However, it is unable to satisfy our target nuclear power demand beyond 2085 because natural uranium reserves run out. That makes this option incompatible with sustainable development, especially since other technologies able to produce sufficient energy (fusion, ...) are still in the research labs.

The best solution with only light water reactors, then, would be plutonium multiple recycling. Besides the fact that such multiple recycling would be a very complex and expensive operation, it would bring nuclear power to a quasi final end. Indeed, the only natural fissile resource $\left({ }^{235} \mathrm{U}\right)$ would be entirely consumed by about 2100 and the left over multi-recycled plutonium would be degraded: it would contain too many elements that do not undergo fission easily so that it could not be used on its own as a reactor fuel.

Other solutions, able to extract close to $100 \%$ of the potential energy content of the raw material thanks to breeding, have to be considered. If the sustainable development of nuclear power is to be achieved, we must resort in the short term, i.e. within the next 10 to 15 years, to reactor types other than light water reactors, to reactors capable of breeding at least as much fissile matter as they consume (isobreeders). In the following sections, we will consider fast neutron reactors based on the U-Pu fuel cycle (sections 4 and 6) and thermal neutron reactors based on the $\mathrm{Th}^{2}{ }^{233} \mathrm{U}$ fuel cycle (sections 5 and 6 ).

\section{Scenario with Light Water and Fast Neutron Reactors}

\subsection{Characteristics of the Fast Neutron Reactors (FNR) Considered}

Of the 6 systems selected by the Generation IV International Forum, four operate with a fast neutron spectrum. Two of these fast neutron reactors, the ones the CEA (french Atomic Energy Commission) is working on, are included in the simulation described in this section: the liquid metal cooled fast reactor (SuperPhenix type) 
and the gas cooled fast reactor. The characteristics of these two reactors are given in Table 7: in this simulation, both have a breeding ratio larger than one. Their fuel is depleted uranium and plutonium. Fuel loading and unloading is done every 5 years in the liquid metal reactor and every 15 years in the gas cooled reactor ${ }^{2}$. Plutonium breeding causes depleted uranium to be consumed in the reactor. The quantity of depleted uranium that has to be input depends on the temperature in the reactor, hence on its thermodynamic efficiency. We set the thermodynamic efficiency at $40 \%$ for all the FNRs in our simulations.

\begin{tabular}{|l||l|l|}
\hline & $\begin{array}{l}\text { Liquid metal } \\
\text { coolant }\end{array}$ & Gas coolant \\
\hline \hline Output capacity & $1.0 \mathrm{GWe}$ & $0.3 \mathrm{GWe}$ \\
\hline First operating date & 2025 & 2025 \\
\hline Lifespan & $50 \mathrm{ans}$ & $60 \mathrm{ans}$ \\
\hline $\begin{array}{l}\text { Fuel amount (per load): } \\
\text { Depleted uranium }\end{array}$ & 48 tons & 51 tons \\
Plutonium & 6 tons & 7 tons \\
\hline $\begin{array}{l}\text { Reprocessing time } \\
\text { Loading periodicity }\end{array}$ & 5 years & 5 years \\
Number of loads & 2 & 15 years \\
\hline Breeding (per reactor-year): & 1 ton & $300 \mathrm{~kg}$ \\
Depleted U input & $300 \mathrm{~kg}$ & $100 \mathrm{~kg}$ \\
Pu output & \multicolumn{2}{|l}{} \\
\hline
\end{tabular}

Table 7: Characteristics of the fast neutron breeder reactors considered.

We have also considered a third type of fast neutron breeder reactor. It is started up with ${ }^{235} \mathrm{U}$ as its fissile element, and breeds the same amounts of plutonium as the liquid metal cooled reactor described above.

The advantage of this third type of reactor is that, since it does not need plutonium for its initial load, there is no need to start a light water reactor to produce plutonium for it. Moreover, ${ }^{235} \mathrm{U}$ is used more efficiently in an FNR than in a light water reactor: a total of 15 tons of ${ }^{235} \mathrm{U}$ are required to start an FNR while a light water reactor consumes 45 tons of ${ }^{235} \mathrm{U}$ to produce the plutonium needed to start a liquid metal cooled fast neutron reactor (two 6 ton loads).

The characteristics of the fast neutron reactor started up with ${ }^{235} \mathrm{U}$ are given in Table 8.

The corresponding deployment scenarios are detailed below, in sub-sections 4.3 to 4.5 .

\footnotetext{
${ }^{2}$ Fuel replacement periodicity depends mainly on the specific power released in the fuel elements, the specific power itself depending on the coolant.
} 


\begin{tabular}{|l||l|}
\hline & \multicolumn{1}{|c|}{$\begin{array}{c}\text { FNR started with }{ }^{235} \mathrm{U} \\
\text { (liquid metal coolant) }\end{array}$} \\
\hline \hline Output capacity & 1.0 \\
\hline First operating date & 2025 \\
\hline Lifespan & 50 yrs \\
\hline $\begin{array}{l}\text { Fuel amount (per load): } \\
\text { Enriched uranium }\end{array}$ & 50 tons \\
${ }^{235}$ U enriching ratio & $15 \%$ \\
\hline Reprocessing time & 5 yrs \\
Loading periodicity & 5 yrs \\
Number of loads & 2 \\
\hline Breeding (per reactor-year): & 1 ton \\
Depleted U input & $300 \mathrm{~kg}$ \\
Pu output & 6 tons \\
\hline Final discharge from reactor: & \\
Pu amount per load &
\end{tabular}

Table 8: Characteristics of the fast neutron breeder reactors started with ${ }^{235} \mathrm{U}$ based fuel.

\subsection{Characteristics of the Light Water Reactors involved}

Table 7 shows that the fissile matter needed for the initial inventory of a 1 GWe $\mathrm{U}-\mathrm{Pu}$ based fast neutron breeder reactor is about equal to the amount of plutonium produced by a standard PWR type light water reactor during its entire lifespan. In order to deploy FNR type reactors, then, the $\mathrm{Pu}$ produced in the EPRs must not be recycled, large amounts of plutonium being necessary for FNR deployment.

The light water reactors involved in this deployment scenario are the existing PWRs (characteristics given in section 3) and the future EPRs described above, with enriched natural uranium fuel (case 1 in Table 6).

\subsection{Scenario with liquid metal cooled FNRs}

The results in terms of installed capacity and uranium and plutonium stockpiles for the nuclear power deployment simulation based on a combination of light water reactors and liquid metal cooled fast neutron breeder reactors are shown in Figures 5 and 6 .

In this scenario, in order to produce, in light water reactors, the plutonium needed for the initial inventory of the FNRs, today's installed PWR capacity has to be multiplied five fold. These light water reactors produce enough plutonium to give the FNRs their initial impulse. Subsequently, breeding in the FNRs provides enough plutonium to continue their growth, they become predominant by 2075 , and the number of EPRs in operation starts to decrease. 


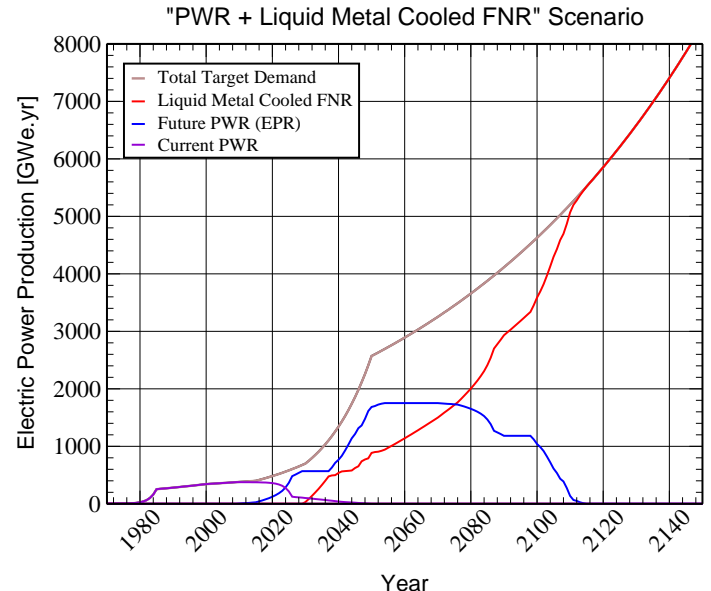

Figure 5: Nuclear power deployment with light water reactors and liquid metal cooled FNRs.
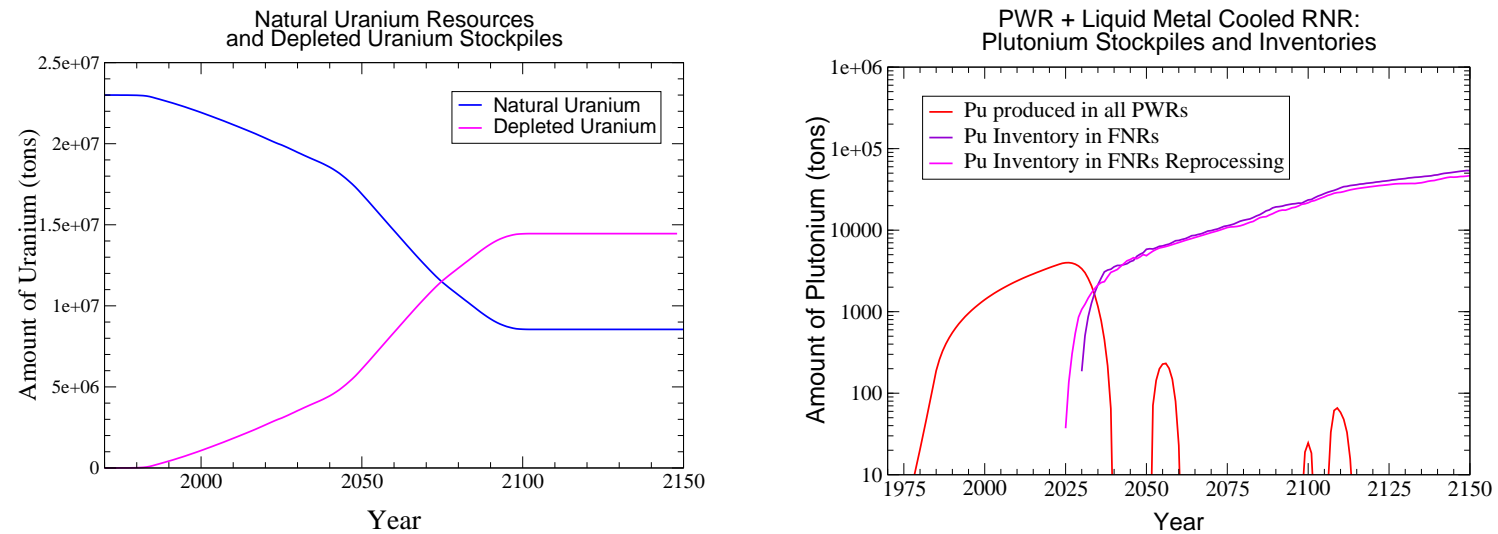

Figure 6: Uranium and plutonium stockpiles corresponding to the deployment of nuclear power with light water reactors and liquid metal cooled FNRs. 
In this scenario, we see that $[10]$ :

- Up to 1500 EPRs have to be started, consuming 15 million tons of natural uranium by 2100 , leaving $35 \%$ of the natural uranium resource still available for future use.

- Large amounts of plutonium are involved: 30000 tons of plutonium in the FNR fuel in 2100, and an equal amount in the reprocessing units. That is a lot of fissile matter!

In sum, this deployment scenario requires complex handling of the fuel and of the minor actinides generated. Moreover, this scenario would not be able to satisfy a significantly larger nuclear power demand (sub-section 2.1) and that possibility cannot be simply brushed off.

\subsection{Scenario with gas cooled FNRs}
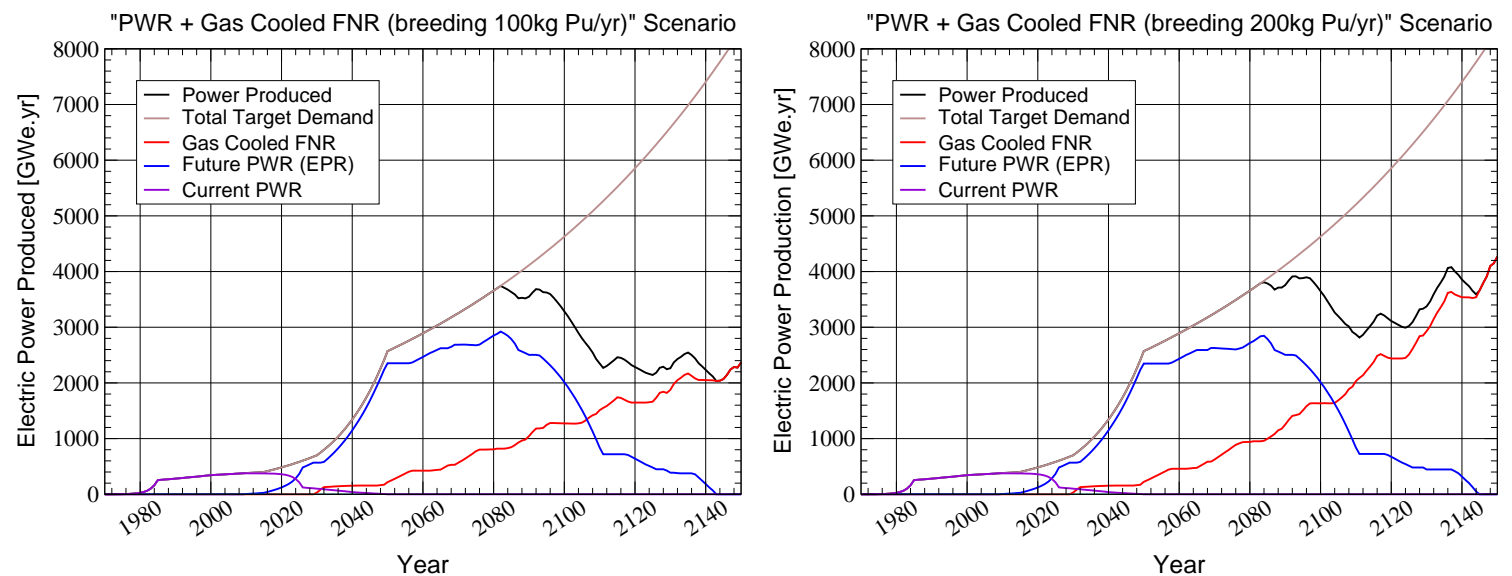

Figure 7: Nuclear power deployment with light water reactors and gas cooled FNRs.

The results in terms of installed capacity and uranium and plutonium stockpiles for the nuclear power deployment simulation based on a combination of light water reactors and gas cooled fast neutron breeder reactors are shown in Figures 7 (left) and 8.

In this scenario, the light water reactors are not able to produce enough plutonium to start the FNRs. EPRs have to continue to run and produce plutonium until, eventually, the natural uranium resource runs out and no new EPR can be started, the remaining uranium being allocated. The target world energy demand cannot be met starting in 2080. Even if the plutonium breeding ratio in these gas cooled FNRs is doubled (Figure 7 - right), an unlikely event since it reaches the theoretical limit of plutonium production without taking neutron losses in the reactor into account, natural fissile uranium starts to run out by 2085. A scenario based on gas cooled FNRs, then, does not satisfy sustainable development criteria in that it leads to a 

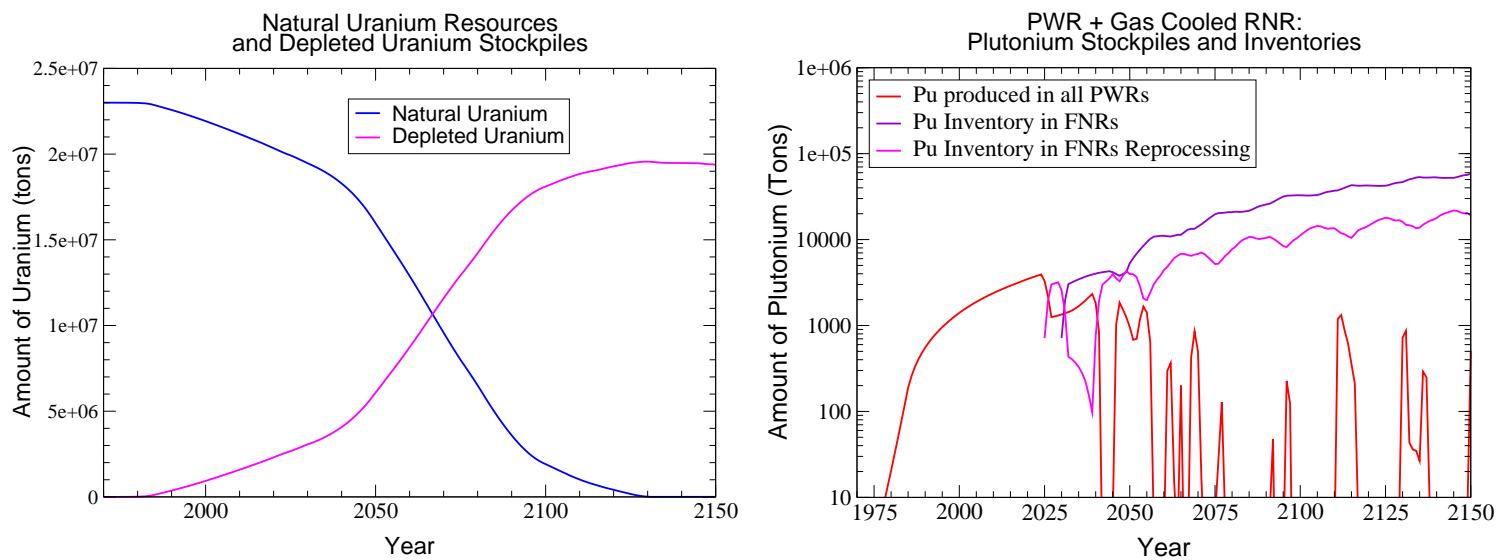

Figure 8: Uranium and plutonium stockpiles corresponding to the deployment of nuclear power with light water reactors and gas cooled FNRs.

rapid depletion of natural fissile uranium reserves.

\subsection{Scenario with liquid metal cooled FNRs started either with Plutonium or with ${ }^{235} \mathbf{U}$}

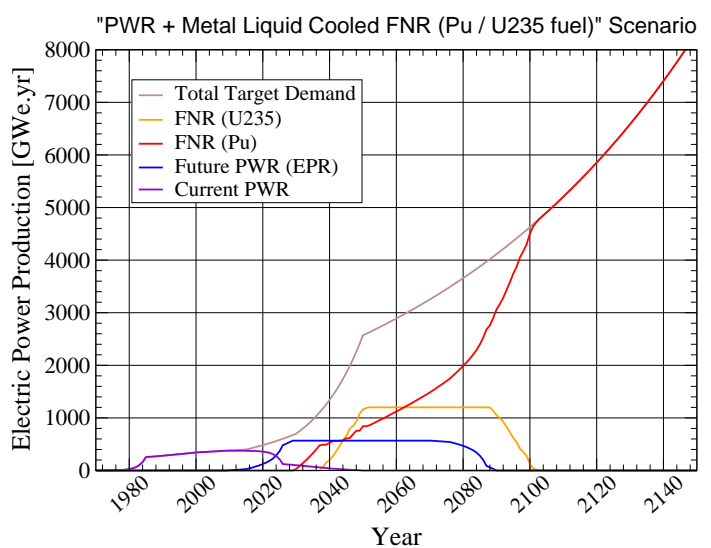

In this scenario, the FNRs started with plutonium are given highest priority, so as to help consume the plutonium stockpiles. If there is not enough plutonium to start an FNR, however, the second priority reactor is an FNR started with ${ }^{235} \mathrm{U}$ instead of, as in the first scenario discussed in sub-section 4.3, an EPR to produce the missing plutonium. The results in terms of installed capacity and uranium and plutonium stockpiles for the nuclear power deployment simulation based on a combination of light water reactors and liquid metal cooled fast neutron breeder reactors started either with plutonium or with ${ }^{235} \mathrm{U}$ are shown in Figures 9 and 10.

The results of this scenario are similar to those of sub-section 4.3, with one difference: enough plutonium is produced with an installed capacity of FNRs started with ${ }^{235} \mathrm{U}$ that is only three times as large as the current PWR capacity. As a result, the pressure on the natural uranium resource is less intense, $55 \%$ of the reserve remains available after 2100. Moreover, the current PWRs are replaced by a quasi 

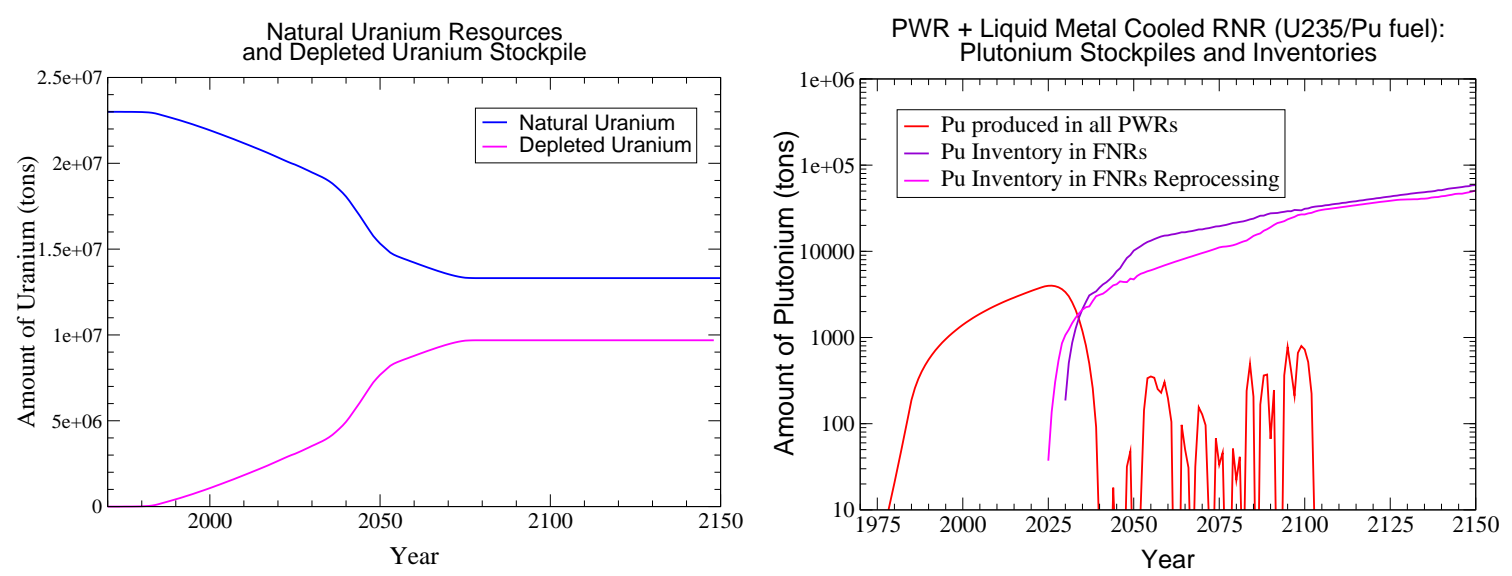

Figure 10: Uranium and plutonium stockpiles corresponding to the deployment of nuclear power with light water reactors and liquid metal cooled FNRs started either with plutonium or with ${ }^{235} \mathrm{U}$.

equal number of EPRs which make the transition towards the FNRs.

Such a deployment scenario could prove useful for countries which do not have plutonium stocks, e.g. countries which don't have any, or have too few, light water reactors.

However, a fleet of FNRs started with ${ }^{235} \mathrm{U}$ would require a large scale uranium enriching industry capable of producing enriched uranium with $15 \%$ fissile matter content.

Moreover, the same amount of plutonium in the fuel cycle and of actinides in the inventories is found in this scenario, implying the same complex handling. Moreover, in the event of a decision to ban nuclear power, e.g. because it is replaced by another source of energy (fusion, ...), the problem arises of how to incinerate these large quantities of plutonium (a total of 60000 tons in 2100) in reactors and in fuel processing plants. A 1 GWe reactor modified to operate as a burner consumes only about 1 ton of plutonium per year. Thus, plutonium incineration would require 60 000 reactor-years, to be compared to the 120000 reactor-years of FNRs being operated in 2100 in this scenario. The incineration of the plutonium stocks produced in this instance appears extremely difficult, it would be an expensive and drawn out process, near to impossible!

\section{Scenario with Light Water and Molten Salt Re- actors}

${ }^{232} \mathrm{Th}$ capture cross sections and ${ }^{233} \mathrm{U}$ capture and fission cross sections are such that breeding can be achieved with a thermal neutron spectrum as well as with a fast neutron spectrum. Breeding with a thermal neutron spectrum requires smaller quantities of fissile material, hence our choice, in this study, of the molten salt reactor 
based on the ${ }^{232} \mathrm{Th}$ (fertile) - ${ }^{233} \mathrm{U}$ fissile) fuel cycle in a thermal neutron spectrum. These molten salt reactors, or MSRs are one of the six reactor types selected by the Generation IV International Forum.

\subsection{Characteristics of the Molten Salt Reactor involved}

Any scenario that involves reactors based on the $\mathrm{Th}^{2}{ }^{23} \mathrm{U}$ fuel cycle requires that ${ }^{233} \mathrm{U}$ be somehow produced since this fissile element is not to be found in nature, nor is it produced in today's reactors. The option of starting MSRs with an initial load containing another fissile element, such as plutonium or ${ }^{235} \mathrm{U}$ is not satisfactory [13] for the following reasons:

- Starting with plutonium generates excessive amounts of minor actinides, in particular ${ }^{244} \mathrm{Cm}$.

- Starting with ${ }^{235} \mathrm{U}$ has the same drawback as plutonium if the ${ }^{235} \mathrm{U}$ is mixed with ${ }^{238} \mathrm{U}$. Moreover, ${ }^{236} \mathrm{U}$ poisoning impairs normal reactor operation during at least 50 years.

The "conversion" of plutonium or ${ }^{235} \mathrm{U}$ to ${ }^{233} \mathrm{U}$, then, has to be given serious consideration. It can be achieved by irradiating thorium in standard reactors: some of the neutrons emitted by the fissions in the reactor will be captured in thorium, eventually yielding ${ }^{233} \mathrm{U}$ after decay. ${ }^{233} \mathrm{U}$ can thus be produced by breeding in thorium blankets placed either in EPRs (next section) or in FNRs, or in both reactor types (section 6). Little information is available today on the production of ${ }^{233} \mathrm{U}$ in EPRs or FNRs but work on this subject is in progress at the "Groupe de Physique des Réacteurs" (Reactor Physics Group) at the LPSC in Grenoble as well as at the "Groupe de Physique de l'Aval du Cycle et de la Spallation" at IPN in Orsay.

The molten salt reactor type considered in these simulations is called the "Thorium Molten Salt Reactor" or TMSR. This concept is detailed in references [10][14][15]. TMSRs are either iso-breeders or breeders (with a breeding ratio larger than one). In order to improve the reactor's breeding capability, a radial thorium blanket is added to the core: escaping neutrons can produce ${ }^{233} \mathrm{U}$ in the blanket.

The characteristics of the TMSR are summarized in Table 9. The fuel is loaded once, when the reactor is first started, and thorium is added on a regular basis to ensure iso-breeding. Half the thorium load is in the reactor core, the other half being in the fuel reprocessing unit associated to the reactor.

\subsection{Characteristics of the Light Water Reactors involved}

The transition light water reactors used in this scenario are today's PWRs and the future EPRs whose fuel is enriched uranium with plutonium multi-recycling as in 


\begin{tabular}{|l||c|}
\hline & TMSR \\
\hline \hline Output capacity & $1.0 \mathrm{GWe}$ \\
First operating date & 2030 \\
Lifespan & $50 \mathrm{yrs}$ \\
\hline Fuel amounts: & 58 tons \\
Thorium & $3 \% / 1.7$ tons \\
Fissile matter $\left({ }^{233} \mathrm{U}\right)$ in fuel & 1 ton \\
\hline Thorium input & 1 ton \\
${ }^{233}$ U produced & $4 \mathrm{~kg}$ \\
Pu produced & 21 tons \\
\hline Thorium blanket: thorium amount &
\end{tabular}

Table 9: Characteristics of the MSRs involved, i.e. TMSRs. The amounts are given per GWe.year of energy produced.

\begin{tabular}{|l||c|}
\hline & Thorium MOX fuel \\
\hline \hline Output capacity & $1.45 \mathrm{GWe}$ \\
First operating date & 2010 \\
Lifespan & $50 \mathrm{yrs}$ \\
\hline${ }^{235}$ U enriching ratio of the fuel & $4.5 \%$ \\
\hline${ }^{235}$ U enriching ratio & $0.25 \%$ \\
of the depleted U rejected & \\
\hline Fuel amount & $13.6 \mathrm{tons}$ \\
\hline Spent fuel to be reprocessed & $12.4 \mathrm{tons}$ \\
\hline${ }^{233}$ U production: & $133 \mathrm{~kg}$ \\
$\quad$ Thorium input & $133 \mathrm{~kg}$ \\
\hline
\end{tabular}

Table 10: Characteristics of future EPRs used to produce ${ }^{233}$ U. Amounts are given per $G W$ e.year of energy generated. 
case 2 of Table 6, now, however, they are producing ${ }^{233} \mathrm{U}$ instead of plutonium, thorium MOX being added in the core. The reason the multi-recycling option is chosen for the EPRs is that, in this scenario, there is no other reactor able to consume the $\mathrm{Pu}$ so that it is the best way to avoid large accumulations of this material. It is assumed that the minor actinides are incinerated in other, future, reactor types such as Accelerator Driven Systems (ADS) or Generation IV burners.

The characteristics of the ${ }^{233} \mathrm{U}$ producing EPRs are given in Table 10.

\subsection{Deployment result with Light Water Reactors and Molten Salt Reactors}
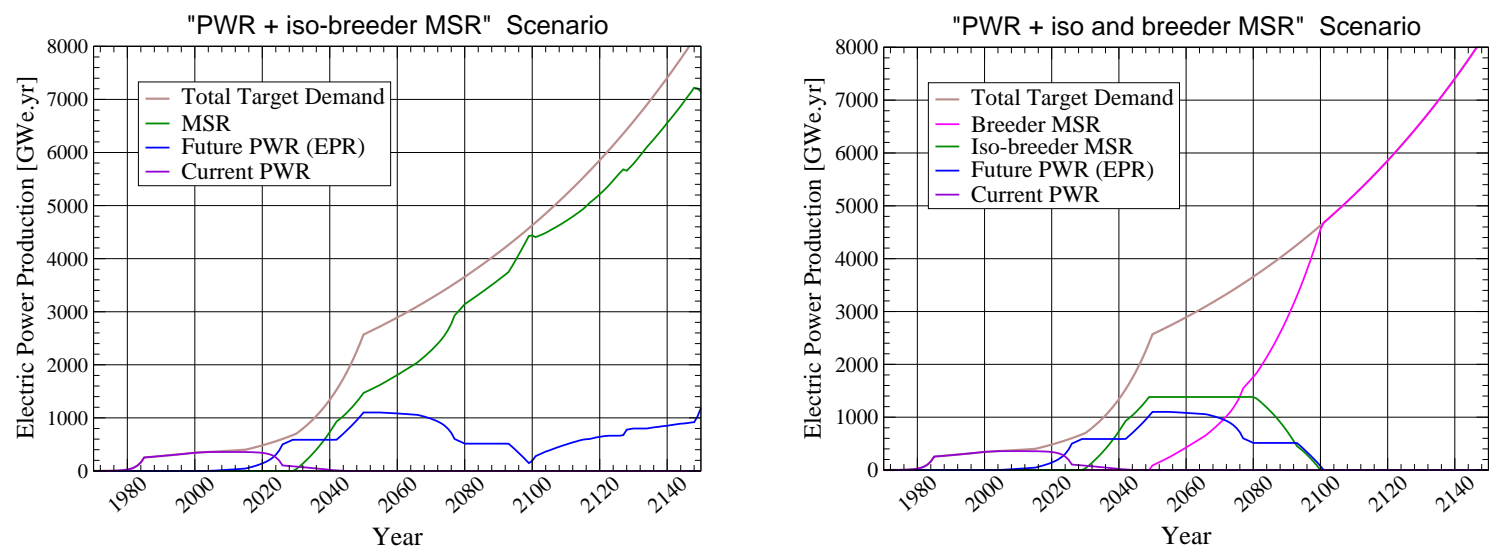

Figure 11: Nuclear power deployment scenario with light water reactors and molten salt reactors that are iso-breeders (left) and iso-breeders, becoming breeders (right).

As shown in Figure 11 (left), this scenario is able to meet the target energy demand, but more than half of the natural uranium reserves are used up (Figure 12). This is because continuous operation of a large number of light water reactors is necessary to produce the ${ }^{233} \mathrm{U}$ needed to start the TMSRs. This problem can be solved if, starting in 2050, the TMSRs are considered capable of breeding approximately $10 \mathrm{~kg}$ of ${ }^{233} \mathrm{U}$ per year. The twenty year delay between the first TMSRs and the TMSRs with a higher breeding ratio corresponds to the time needed to develop an optimized TMSR technology. The results obtained with this option are shown in Figure 11 (right). As Figure 12 shows, only one third of the natural uranium reserves is consumed. Sensitivity tests have shown that a slight variation in the production of ${ }^{233} \mathrm{U}$ in the light water reactors or a small variation of the ${ }^{233} \mathrm{U}$ inventory in the TMSRs does not modify the results of this scenario in any significant way.

A problem remains: the stocks of plutonium produced in the light water reactors, even if they are twenty times less abundant than in the previous scenario (subsection 4.5), will have to be incinerated. A possibility is the one examined in the next section, a solution that also includes fast neutron reactors. These can make 


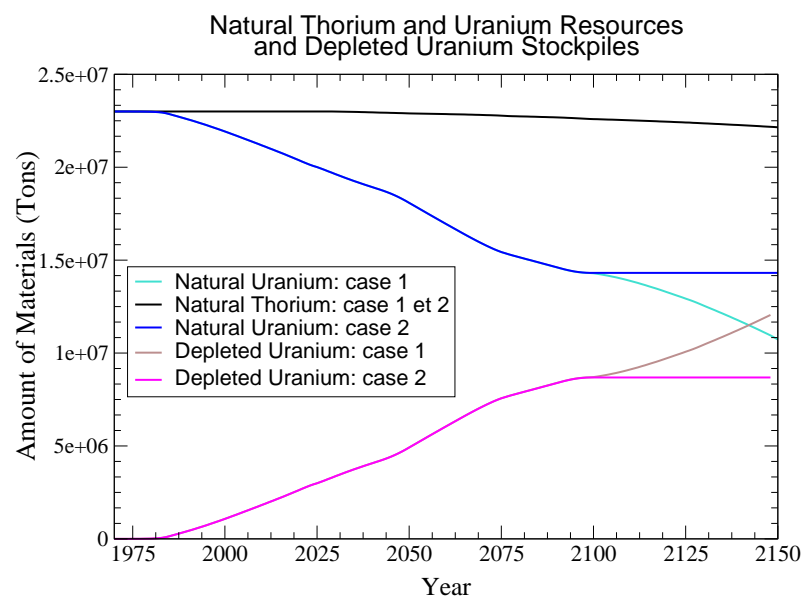

Figure 12: Natural uranium and thorium stocks, and depleted uranium stockpile in nuclear power deployment with light water reactors and molten salt reactors that are isobreeders (case 1) and iso-breeders, becoming breeders (case 2).

efficient use of the plutonium and thus close the fuel cycle.

\section{Scenario with Light Water Reactors, FNRs and TMSRs}

This optimized scenario calls on the three types of reactors described in the previous sections, so as to make an efficient transition from today's reactors towards a sustainable reactor technology that implies breeding. In this scenario the ${ }^{233} \mathrm{U}$ that is needed in the molten salt reactors is bred in solid thorium blankets in the EPRs and in the FNRs that are deployed.

\subsection{Characteristics of the Light Water Reactors involved}

The transition light water reactors in this scenario are today's PWRs and the future EPR type reactors using an enriched uranium fuel with no plutonium or minor actinide recycling (case 1 in Table 6) but, in this instance, they produce some ${ }^{233} \mathrm{U}$. For this purpose, a thorium blanket is added to the core. The reason the plutonium and minor actinide multi-recycling option is not chosen for this scenario is that the plutonium and minor actinides can be consumed more efficiently in the FNRs.

The characteristics of these ${ }^{233} \mathrm{U}$ producing EPRs are given in Table 11.

\subsection{Fast Neutron Reactors involved}

Only one of the fast neutron reactor types described in section 4 has been considered here: the liquid metal cooled reactor whose characteristics are better known. The FNRs here, consume plutonium to breed ${ }^{233}$ the result being that plutonium stocks are reduced and the ${ }^{233} \mathrm{U}$ needed to start the MSRs is produced. 


\begin{tabular}{|c|c|}
\hline & UOX fuel \\
\hline Output capacity & $\overline{1.45 \mathrm{GWe}}$ \\
\hline First operating date & 2010 \\
\hline Lifespan & $50 \mathrm{yrs}$ \\
\hline${ }^{235} \mathrm{U}$ enriching ratio of fuel & $4.9 \%$ \\
\hline $\begin{array}{l}{ }^{235} \mathrm{U} \text { enriching ratio of } \\
\text { depleted uranium rejected }\end{array}$ & $0.25 \%$ \\
\hline Fuel amount & 13.6 tons \\
\hline Spent uranium to reprocess & 12.6 tons \\
\hline Pu produced to reprocess & $130 \mathrm{~kg}$ \\
\hline $\begin{array}{l}{ }^{233} \mathrm{U} \text { production: } \\
\text { Thorium input } \\
{ }^{233} \mathrm{U} \text { produced }\end{array}$ & $\begin{array}{l}130 \mathrm{~kg} \\
130 \mathrm{~kg}\end{array}$ \\
\hline
\end{tabular}

Table 11: Characteristics of the future ${ }^{233}$ U producing EPRs. Amounts of material are given per $G W$ e.year of energy generated.

The characteristics of these FNRs are given in Table 12 .

\begin{tabular}{|l||l|}
\hline \multicolumn{1}{|c||}{} & Liquid metal coolant \\
\hline \hline Output capacity & $1.0 \mathrm{GWe}$ \\
\hline First operating date & 2025 \\
\hline Lifespan & $50 \mathrm{yrs}$ \\
\hline Fuel amount (per load): & 48 tons \\
Depleted U & $11 \% / 6$ tons \\
Fissile matter (Pu) in fuel & $5 \mathrm{yrs}$ \\
\hline Reprocessing time & $5 \mathrm{yrs}$ \\
Loading periodicity & 2 \\
Number of loads & 1 ton \\
\hline Depleted U input per year & $200 \mathrm{~kg}$ \\
Pu input per year & $500 \mathrm{~kg}$ \\
Th input per year & $500 \mathrm{~kg}$ \\
233 U production per year &
\end{tabular}

Table 12: Characteristics of the ${ }^{233} U$ breeding fast neutron reactors involved in this scenario.

\subsection{Molten Salt Reactors involved: TMSR}

The molten salt reactors considered here are TMSRs, whose characteristics are discussed in the preceding section and summarized in Table 9. The ${ }^{233} \mathrm{U}$ needed to start the TMSRs is produced both in the EPRs and in the FNRs in this scenario. As FNRs continue to operate during the entire duration of the scenario, sufficient 
amounts of ${ }^{233} \mathrm{U}$ are constantly available and breeding is not necessary in the TMSRs. As a consequence, iso-breeding TMSRs are used in this scenario.

\subsection{Deployment Results including Light Water Reactors, Liquid Metal Cooled FNRs and TMSRs}

With this scenario, as shown in Figure 13, today's reactors are fully replaced by 2030 with EPR type light water reactors. The EPRs are progressively replaced with FNRs and TMSRs and they are shut down in 2080 or so. The transition towards sustainable Generation IV reactors is then complete.

The ${ }^{233} \mathrm{U}$ needed to start the TMSR reactors can be produced by the same number of light water reactors as we have today, plus an equivalent number of FNRs. Molten salt reactors are dominant by 2035 and their breeding capability makes for successful development of nuclear power beyond that date.

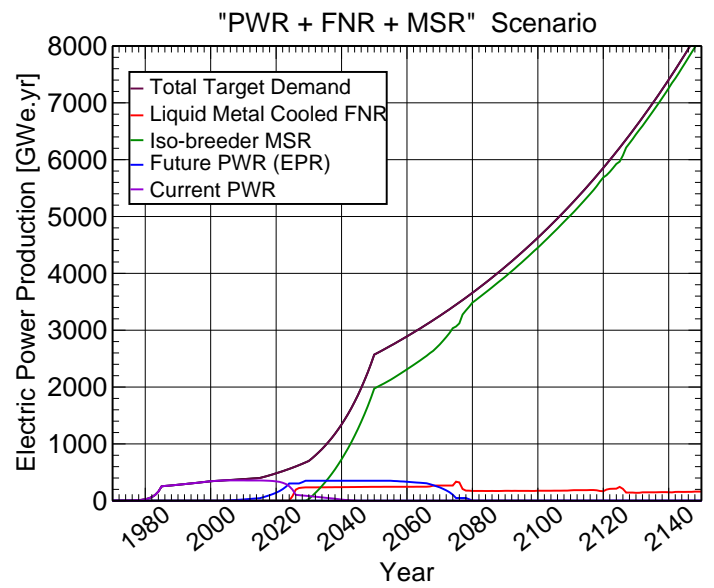

Figure 13: Nuclear power deployment with light water reactors, liquid metal cooled FNRs and TMSRs.

As for the plutonium produced, it is in the inventory of the FNRs; Figure 14 (right) shows that the maximum amount built up is ten times less than in the deployment scenario with only light water reactors and liquid metal cooled FNRs. In order to make sure the plutonium produced in the light water reactors is consumed, we have chosen to set the highest priority on FNR type reactors as long as enough plutonium is available. Figure 14 (right) shows that the plutonium accumulated before the first FNRs are started is divided by two in 2100. In this scenario, the U-Pu fuel cycle is closed thanks to the FNRs.

The target nuclear power demand is met during the entire duration of the scenario (Figure 13) and this is achieved without draining the natural uranium and thorium reserves (Figure 14 - left). Only one third of the natural uranium and a tiny fraction of the thorium reserves are consumed during the entire time period considered for the deployment. As a consequence, a larger demand could be met without difficulty.

We find, then, that this scenario based on the three reactor types considered in our simulations is, by far, the most efficient. It offers faster and more flexible 

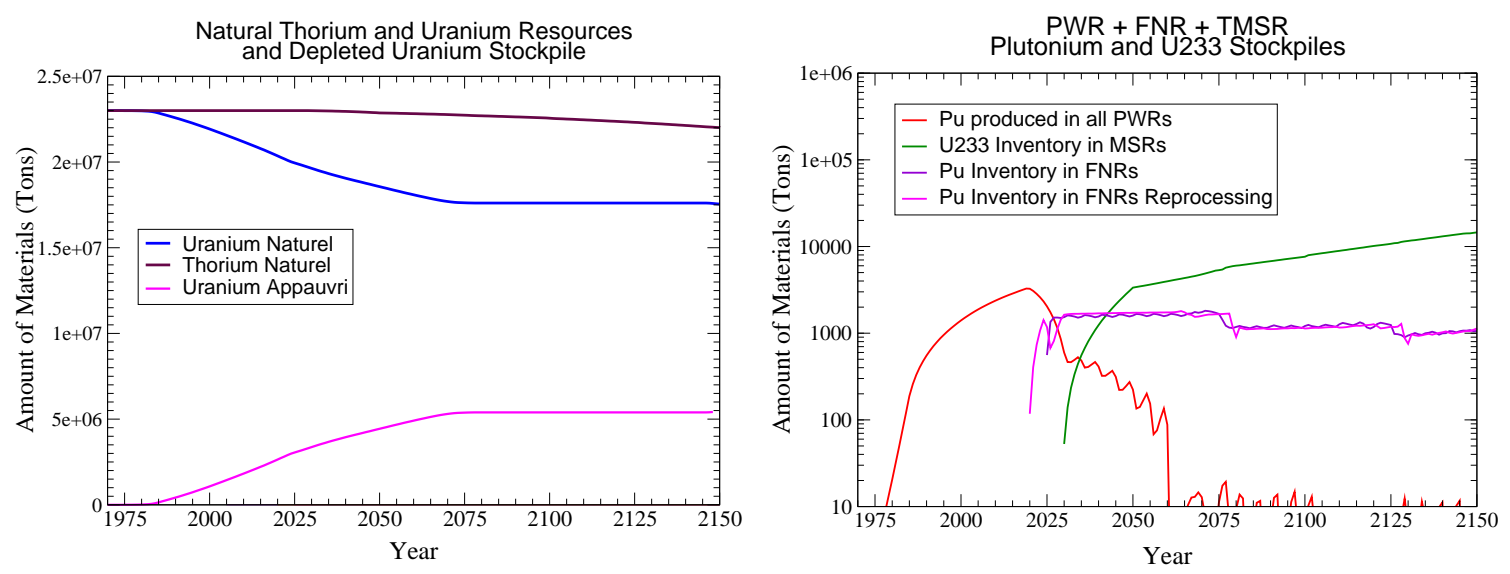

Figure 14: Natural uranium and thorium reserves, plutonium and ${ }^{233} U$ stockpiles corresponding to the deployment of nuclear power with light water reactors, liquid metal cooled FNRs and TMSRs.

deployment than any of the other scenarios, and also faster and more flexible shut down if need be. Indeed, TMSRs operate with little fissile matter. A TMSR, if it is modified to operate as an incinerator, can burn up to one ton of ${ }^{233} \mathrm{U}$ per year, i.e. practically a full load of fissile matter. This could allow a nuclear power shut down without leaving behind fissile matter stockpiles such as those of the scenario discussed in section 4.5.

We note also that the amounts of plutonium and minor actinides produced are significantly (several orders of magnitude) smaller than in the other scenarios. This makes waste management and, as a result, the whole deployment process, simpler and easier to implement.

Finally, in the event that all the reactors would have been shut down and the residual fissile matter fully incinerated, if the need to start nuclear power again were to arise, there would still be enough natural uranium to do so.

This scenario brings to light the importance of the $\mathrm{Th}^{2}{ }^{23} \mathrm{U}$ fuel cycle in general and, more specifically, that of the molten salt reactor concept: efficient and sustainable nuclear power deployment is achievable, in conjunction with optimized fissile matter use and waste production.

A palette of intermediate scenarios can be considered, ranging from the option with only light water reactors and FNRs of section 4 to the option in this section, with the three types of reactors and a predominance for molten salt reactors. Such intermediate scenarios would change the number of FNRs with a resulting build up of plutonium stockpiles lying between those of Figure 10 and of Figure 14. 


\section{Conclusions and Prospects}

This study is based on an eight fold increase of nuclear power in 2050, from today's nuclear power capacity, and this may be a low figure. We examined the means already available, or that should be developed, in order to meet this demand in a sustainable way.

With nuclear power production continued with the same means as today, i.e. with light water reactors, even with the most favorable scenario, i.e. with plutonium multi-recycling and optimized handling of ${ }^{235} \mathrm{U}$, the target worldwide nuclear power demand cannot be met beyond 2085 for lack of natural uranium, the reserves being drained. This, of course, is incompatible with the notion of sustainable development in the present context where alternate energy production technologies (fusion, ...) are still in the research labs. Moreover, such multi-recycling would be complex and expensive and it would, in addition, damage the plutonium, the only fissile material available once the natural resources have completely run out. Restarting nuclear power production in any significant way would then be very expensive.

The second option we explored is a combination of light water reactors and fast neutron reactors. The best scenario in this category is able to meet the target worldwide nuclear power capacity during the entire time interval considered. However, it leads to the accumulation of large amounts of plutonium and minor actinides residing in the reactors and the fuel reprocessing units, implying complex handling procedures. Moreover, in the event that nuclear power generation is stopped, e.g. because it can be replaced by another source of energy (fusion, ...) the incineration of the plutonium stockpiles is a problem, this incineration being difficult, expensive, drawn out, near to impossible. Restarting nuclear power production after having stopped it, here again, would prove very expensive.

The third option considered in this study is a combination of light water reactors and molten salt reactors based on the Th- ${ }^{233} \mathrm{U}$ fuel cycle. In this case also, the target worldwide nuclear power capacity can be met over the full duration, but significant stockpiles of deteriorated plutonium are accumulated with no incineration possibilities so that the fuel cycle of the light water reactors is not closed.

Finally, the last option examined consists in a combination of the three reactor types considered in the course of this study, light water reactors, fast neutron reactors and molten salt reactors. This appears to be, by far, the most efficient scenario. It allows the fastest and most flexible deployment as well as the fastest and most flexible stopping of nuclear power if such a decision were to be made. The role of the fast neutron reactors is also to close the U-Pu fuel cycle and the amounts of plutonium and minor actinides produced are significantly smaller than in the preceding options. As a result, waste management is made simpler and easier to implement. Nuclear power deployment in this case is sustainable and efficient, the use of fissile matter and the production of wastes are optimized.

We would like to stress, here, that some of the data used for these simulations, in 
particular plutonium breeding ratios and the production of ${ }^{233} \mathrm{U}$ in EPRs and FNRs come from estimations. Better founded data will be obtained thanks to a CNRS research program that is in progress at the "Groupe de Physique des Réacteurs" at LPSC in Grenoble and at the IPN in Orsay. Preliminary tests have established that the conclusions reached here are not very sensitive to the hypotheses formed on these system characteristics.

This study will be continued in order to include, in particular, some local aspects of the deployment. On one hand, difficulties may appear, e.g. the need to exchange or transport fissile and/or radiotoxic materials between regions, or risks of proliferation. On the other hand, all countries are "not equal" vis à vis nuclear power. It would be interesting to study the future deployment of nuclear power in two distinct types of regions, i.e.:

- In a region like Europe which already has a number of light water reactors and, as a consequence, fair amounts of plutonium, in which the growth of nuclear power will be moderate in the next 100 years. A scenario based on a combination of light water reactors and FNRs is valid here, if other regions resort to the $\mathrm{Th}^{2}{ }^{23} \mathrm{U}$ fuel cycle.

- In an area like Southeast Asia, whose energy demand and, as a consequence, whose demand on nuclear power, will grow rapidly in the coming years. Here, a scenario based solely on light water reactors would be unrealistic, as would be a scenario based on a combination of light water reactors and FNRs, which would require large amounts of plutonium. Here, an option including molten salt reactors would be much more flexible and would allow faster growth, it would be particularly well adapted.

The global scenarios presented in this paper illustrate the limitations that worldwide nuclear power deployment suffers while demonstrating how complementary the different reactor types are. This study brings to light the strongly constraining fact that sufficient amounts of fissile matter must be available if breeder reactors are to be started. Besides, these breeder reactors will not be industrially available before 20 to 25 years from now. In order to ensure the growth of nuclear power and its transition towards a sustainable reactor fleet, then, it is necessary to build second and third generation reactors.

Our study shows that a global and balanced solution is available, which reconciles fuel cycle closing, non depletion of the natural resource, reduced production of long lived wastes and the possibility of stopping/restarting nuclear power generation rapidly. It rests on a combination of light water reactors and breeder reactors which are necessary to burn the plutonium and produce ${ }^{233} \mathrm{U}$, and on the $\mathrm{Th}-{ }^{233} \mathrm{U}$ fuel cycle which we feel cannot be circumvented. 


\section{Acknowledgments}

We would like to thank particularly Elisabeth Huffer for the work of translation and for her advice all along the writing of the paper. Many thanks to all the members of the "Groupe de Physique des Réacteurs" at LPSC in Grenoble and to Sylvain David from IPN in Orsay for their suggestions and comments which helped us to improve this document. Finally we are specially grateful to Ludovic Mathieu for his significant contribution to a better understanding of the Molten Salt Reactor.

\section{References}

[1] "L'énergie nucléaire d'ici 2050, une réflexion et des recommandations d'un groupe de scientifiques du CNRS dans le cadre du Programme Energie du CNRS", Groupe d'Analyse Thématique 11-a "Nucléaire du futur - Fission", J.-M. Loiseaux et al, CNRS/PACE/DIR 2004.1 (in french).

[2] "The Future of Nuclear Power, An Interdisciplinary MIT Study", http://web.mit.edu/nuclearpower, Massachusetts Institute of Technology, Chapter 4, 2003.

[3] "Programmes de simulation du déploiement de l'électro-nucléaire dans l'environnement DALI : module Scénarios Du Futur", D. Heuer et E. Merle-Lucotte, internal note (http://lpsc.in2p3.fr/gpr/french/gpr.html), 2004 (in french).

[4] "Un point de vue sur les besoins et les approvisionnements en énergie à l'horizon 2050", R.P. Bauquis, La revue de l'Energie $N^{\circ}$ 509, septembre 1999 (in french).

[5] "Scenarios with an Intensive Contribution of Nuclear Energy to the World Energy Supply", H. Nifenecker, D. Heuer, J.M. Loiseaux, 0. Méplan and A. Nuttin, Int. J. Global Energy Issues, Vol. 19, No. 1(2003), 63-77.

[6] "Modèle POLES du LEPII-EPE : résultats préliminaires à l'horizon 2050", P. Criqui, Laboratoire d'Economie de la Production et de l'Intégration Internationale (LEPII), département Energie et Politiques de l'Environnement (EPE), Grenoble, France, private comunication (2004).

[7] "Les Centrales Nucléaires dans le Monde", ELECNUC, CEA, 2003 (in French).

[8] "Scénarios CNE : réacteurs classiques, caractérisation à l'équilibre", C. de Saint Jean, M. Delpech, J. Tommasi, G. Youinou, P. Bourdot, rapport CEA DER/SPRC/LEDC/99-448, 2000 (in French). 
[9] "Plutonium and Americium Multirecycling in the European Pressurized Reactor (EPR) Using Slightly Over-Moderated U-235 Enriched MOX Fuel Assemblies", G. Youinou, F. Varaine, A. Vasile, International Conference on Advanced Nuclear Energy and Fuel Cycle Systems (Global 2003), New Orleans, USA, 2003.

[10] "Molten Salt Reactors and Possible Scenarios for Future Nuclear Power Deployment", E. Merle-Lucotte, L. Mathieu, D. Heuer, J-M. Loiseaux et al, Proceedings of the Physor 2004 conference The Physics of Fuel Cycles and Advanced Nuclear Systems: Global Developments, American Nuclear Society (Ed.) (2004) 1-12

[11] "Les ressources d'uranium fissile permettent-elles de répondre à une forte croissance de l'énergie nucléaire mondiale ?", J.F. Luciani et A. Simon, rapport CEA HC/AS/em/2002-192, octobre 2002 (in French).

[12] "Uranium 2001: Resources, Production and Demand", OECD Publishing / International Atomic Energy Agency (IAEA), 2002.

[13] "Potential of Thorium Molten Salt Reactors: Detailed Calculations and Concept Evolution With a View to Large Scale Energy Production", A. Nuttin, D. Heuer et al., Progress in Nuclear Energy, Vol. 46, No.1, pp. 77-79, 2005.

[14] "The Thorium Molten Salt Reactor: Moving on from the MSBR", L. Mathieu, D. Heuer et al, submitted to Progress in Nuclear Energy (2005).

[15] "Cycle Thorium et Réacteurs Sel Fondu : Exploration du champ des Paramètres et des Contraintes définissant le Thorium Molten Salt Reactor", L. Mathieu, PhD thesis, Institut National Polytechnique de Grenoble, France (2005) (in French). 